DOI: $10.54631 /$ VS.2021.S-66-78

\title{
BUILDING SOUTH VIETNAMESE DELTA SETTLEMENTS IN THE WHIRLWIND OF CLIMATE CHANGE Marion Reinosa
}

\begin{abstract}
Deltaic settlements worldwide are facing unprecedented challenges. This is especially the case in the Mekong Delta, where high population density, capital, and service provision increasingly intersect to expose vulnerable communities to the adverse effects of climate change. Due to a limited understanding of climate change, the presence of unique hydrological phenomena, and anthropogenic actions, the complex situation of the delta and its settlements has led to the implementation of inadequate architectural and urban solutions. This has caused abrupt socio-economic changes, shifting from an ecological integration mindset to a normative and disruptive approach resulting in the imposition of unsuitable models.

Community capacity, which includes low-cost, circular and reuse practices, can offer more ecological perspectives on sustainable building in the delta. Illustrating local in-depth environmental expertise, communities have developed socially and environmentally adapted construction cultures. This paper argues for an alternative paradigm in which cities and settlements promote and integrate local building knowledge to enable architectural and urban forms to play a leading role in the resilience of South-Vietnamese deltaic cities and to mitigate developmental impact on the environment.

Findings show a diversity of options and capacities at the local scale and flexibility in housing design. They also show that persistent gaps in policymaking and inconsistent perception of risk affects architectural and urban climate resilience. The discussion and conclusion advance the potential of local capacity in the building of South-Vietnamese deltaic cities, the need to integrate local knowledge and community capacity into policy, and the necessity to better assess local perception barriers to formulate localised, integrated and multisector policies to build resilient and sustainable South-Vietnamese settlements.
\end{abstract}

Keywords: urbanisation, climate change, housing adaptation, community capacity, risk perception.

For citation: Reinosa Marion (2021). Building South Vietnamese Delta Settlements in the Whirlwind of Climate Change. Russian Journal of Vietnamese Studies, Special issue: 66-78.

\section{Introduction}

With $70 \%$ of its population living in coastal and low-lying areas, Vietnam is among the most vulnerable countries to climate change. Since the end of the war in 1975 and the positive socioeconomic progress associated with opening up, the country has experienced high rates of urbanisation. Projections estimate a $57 \%$ increase in the urban population by 2050 [Garschagen 2010].

Globally, human settlements are responsible for high GHG emissions and land artificialisation. Building and housing policy is often not prioritised, despite their potential impact on climate adaptation. In the Vietnamese Mekong Delta (VMD) human settlements are facing large transformations in an already fragile and highly anthropized environment. Given the centralised power of the state and limited knowledge of the delta's ecological system [Miller 2007], the current approach to climate change by local actors makes little distinction between the effects of climate change, anthropogenic extractive causes and local hydrological phenomena. Most of the settlements 
in the VMD are becoming increasingly impervious to water due to a "hard" infrastructure approach to development, which undermines the absorptive capacity of the delta and can exacerbate flooding. This stands in contrast to the 'free adaptation mechanism', which uses flexible, local 'soft mechanisms' to cope with annual disturbances, by introducing forced adaptation processes [Biggs 2011]. VMD settlements have therefore shifted from an ecologically integrative mindset to a normative and disruptive approach, imposing maladaptive patterns in human settlement construction and exacerbating ongoing challenges.

Many local challenges are the result of past developments, based on ideologies of centralised water control rather than on supporting local adaptation to changes and variability [Biggs et al. 2009: 203]. Given that Vietnam is a country where construction has not yet been professionalised, community capacity can play a central role in the sustainable construction of human settlements for climate mitigation, adaptation and resilience. Utilizing design and construction methods using locally available materials, these capacities can reinvigorate a historical and cultural understanding of human-environment coexistence at the local scale [Tran Thong Anh 2020: 175]. Resorting to designs and construction methods that use locally available resources to meet local needs, illustrating a historical and cultural understanding of human-environment coexistence at the local scale [Ibid.], communities have developed and continue to develop socially and environmentally appropriate growth [Vellinga 2005: 5]. This paper therefore explores an approach that considers community capacity, vernacular (not traditional) architecture and urbanism as a locus of indigenous knowledge and innovation for building more socially and environmentally sustainable settlements.

While acknowledging the complexity of local situations and the changes underway, this paper identifies community building processes and their drivers in selected VMD settlements, reflecting on their potential inclusion in urban and housing policies. Based on field observations, this research explores locally developed socio-technical processes, their conditions of existence, their limitations, and reasons for the disconnect between approaches and discourses. The methodology section presents the means of data collection in settlements and provides a literature review. Findings demonstrate the diversity of options and capacity, the flexibility in housing design, the persistent gaps in policy, and the influence of risk perception and 'modern' ideas on settlement development. The discussion explores the potential of local capacity, the challenge of integrating local knowledge into policy and the barriers of perception in greater detail. The paper concludes by highlighting the opportunities and constraints in developing alternative approaches to south Vietnamese cities.

\section{Objective, material and method}

Using a qualitative methodology between social science and engineering, this paper focuses on selected human settlements along the Chau Doc - Soc Trang transect (Fig.1).

\section{Physical and human context of the studied area}

Home to nearly 18 million people, the VMD is one of the largest delta systems in the world [Nguyen Hoang et al. 2016: 2303]. As the country's rice bowl, the delta's rapid development has led to intensifying human activities and rapid urbanisation, with negative impacts on the environment. However, due to the fragmentation of existing policies, the delta faces many governance obstacles to sustainable development. In light of its relatively recent development (compared to the Red River Delta in the North), intense climate vulnerability, and the presence of significant hydrologic and climatic events, the VMD is a fitting research laboratory in which to document community responses to shocks and their potential for resilience. 


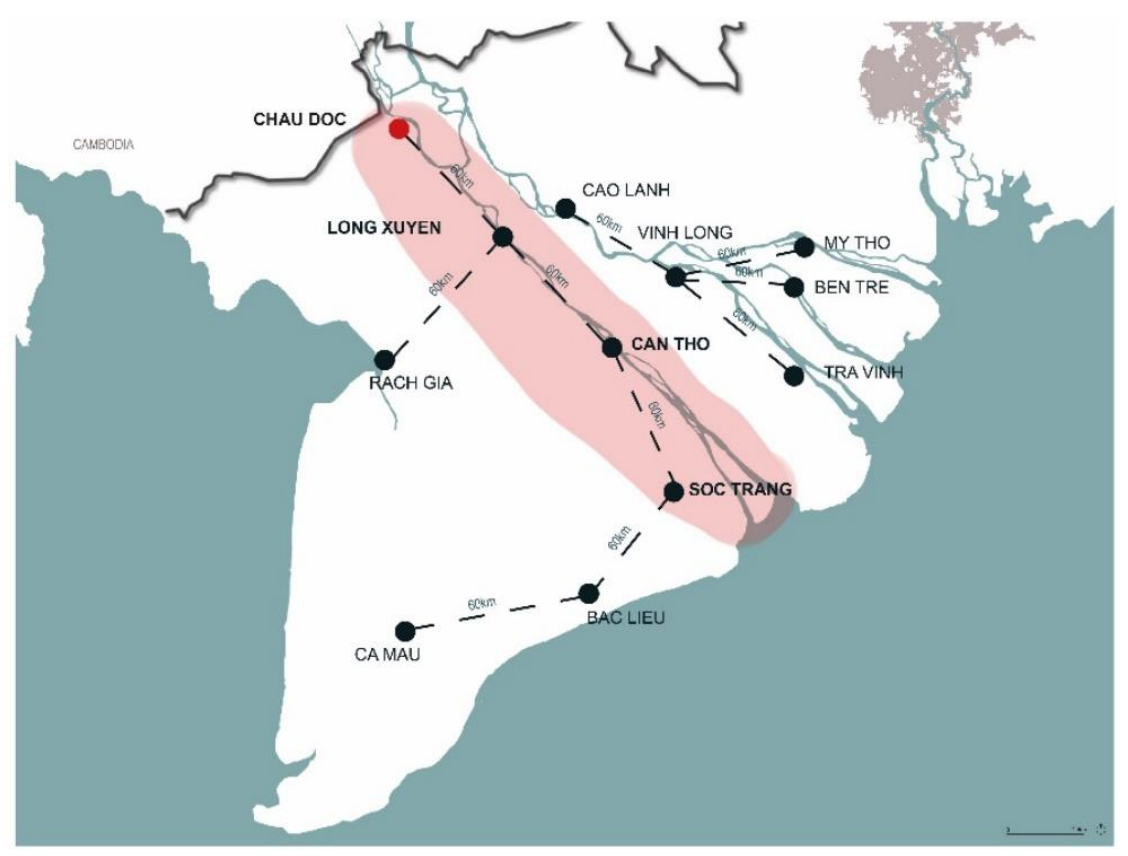

Fig. 1. Location of the Chau Doc-Soc Trang transect. Author's drawing

The selected Chau Doc - Soc Trang transect includes diverse geographical and cultural contexts. This paper focuses on urban fringes and new urban areas of Chau Doc, Long Xuyen, Can Tho and Soc Trang. During observation, these areas showed distinct local knowledge due to their fluctuating settings. Strongly influenced by fluvial processes in the upper delta (annual flooding) and marine processes (tides), as well as by tropical monsoon systems [Tran Thong Anh 2020: 165], this transect has been extensively anthropized by canal construction and agricultural expansion. This has changed the nature of the delta and altered the hydrology of the basin, reducing flooding periods and causing alarming ecological degradation, making the observation of transformations and local communities relevant [Christoplos et al. 2016].

\section{Qualitative data collection and analysis}

At first, data were collected through periods of anthropological observation of living and building processes. These observations enabled the development of preliminary hypotheses. During this phase, ways of living and using spaces throughout the day, buildings, mobility, and daily rhythms were explored and mapped. These sessions were supplemented by semi-structured interviews and focus group discussions with local households to gather quantitative information about their methods of constructing habitats and urban typologies, skills, and daily activities. Interviewees were encouraged to explain their lifestyles, professional occupation, community structures, land status, and understanding of their living environment (Table 1). 
Table 1. Research locations and type of data collection

\begin{tabular}{|c|c|c|c|}
\hline Location & Date & Context & Type of data collection used \\
\hline Chau Doc & $\begin{array}{l}\text { April }- \text { May } \\
2017\end{array}$ & $\begin{array}{l}\text { Riverbanks settlements (dry } \\
\text { season) }\end{array}$ & $\begin{array}{l}\text { Observations, group discussions with local } \\
\text { communities (about } 19 \text { households } \\
\text { interviewed), houses mapping. }\end{array}$ \\
\hline Chau Doc & $\begin{array}{l}\text { Sept. - October } \\
2018\end{array}$ & $\begin{array}{l}\text { Riverbanks settlements, } \\
\text { floating communities, and } \\
\text { resettlement villages (wet } \\
\text { season) }\end{array}$ & $\begin{array}{l}\text { Photographic mapping and semi-structured } \\
\text { interviews, resettlement communities. }\end{array}$ \\
\hline Can Tho & October 2018 & $\begin{array}{l}\text { New urban districts } \\
\text { (Workshops with local } \\
\text { authorities and the Hanoi } \\
\text { Architectural University) }\end{array}$ & $\begin{array}{l}\text { Observations, group discussions with local } \\
\text { communities and local authorities (10 } \\
\text { households interviewed), urban mapping, }\end{array}$ \\
\hline $\begin{array}{l}\text { Long } \\
\text { Xuyen }\end{array}$ & October 2018 & City centre & $\begin{array}{l}\text { Photographic mapping, informal } \\
\text { discussions with local communities. }\end{array}$ \\
\hline Sa Dec & April 2019 & Riverbanks and Canals & $\begin{array}{l}\text { Observations, photographic mapping, } \\
\begin{array}{l}\text { informal discussions with local } \\
\text { communities. }\end{array}\end{array}$ \\
\hline Soc Trang & April 2019 & $\begin{array}{l}\text { Riverbanks areas and urban } \\
\text { centre }\end{array}$ & Observations, photographic mapping. \\
\hline Chau Doc & June 2019 & Floating communities & $\begin{array}{l}\text { Observations, architectural and urban } \\
\text { mapping, semi-structured interviews }(8 \\
\text { households interviewed). }\end{array}$ \\
\hline
\end{tabular}

Additionally, capturing the architectural and urban transformations in a constantly changing environment was fundamental to understanding local contexts. An experimental "transformation mapping" methodology was developed using photographic mirrors (photographing the same place at different times of the year) to capture urban cycles, rhythms, and transformations (Fig. 2)
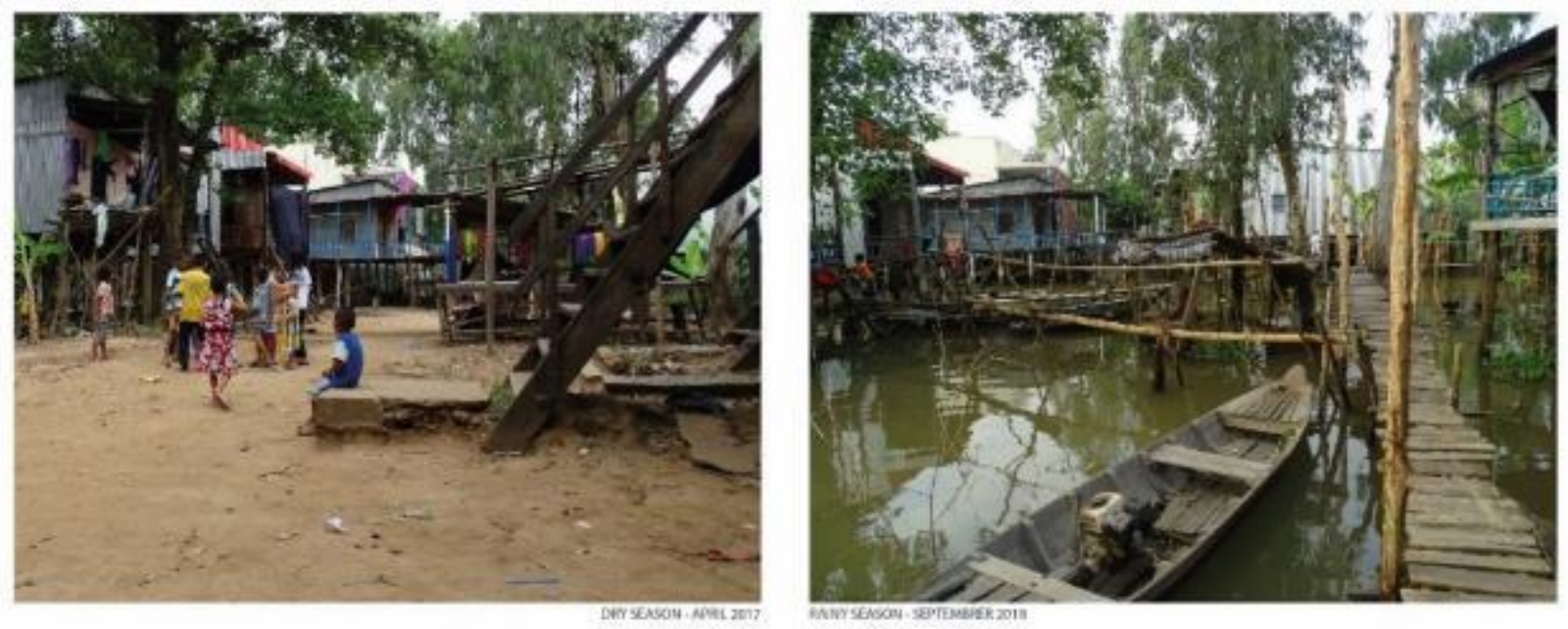

Fig. 2. Examples of photographic mirrors in the surroundings of Chau Doc. Pictures were taken in the dry and rainy seasons to show changes in ways of living and using spaces. Photos of the author

Finally, a lexicon was developed to capture the interpretations and translations between Western and Eastern concepts. This was created to apprehend language the impact of language on biases and perceptions. The lexicon identifies the richness and potential of local terminology to reconceptualize the sustainability of existing coping mechanisms and to advocate for local practices use in sustainable development. 
Table 2. Examples from the lexicon

\begin{tabular}{|c|c|c|c|}
\hline Vietnamese & Meaning/idea & French & Meaning/idea \\
\hline \begin{tabular}{|l|} 
Cảnh quan \\
(landscape)
\end{tabular} & $\begin{array}{l}\text { cảnh: scenery, site, place } \\
\text { quan : to observ, to be } \\
\text { concerned (quan tâm), } \\
\text { contemplate (quan sát) }\end{array}$ & Paysage & $\begin{array}{l}\text { Picture } \\
\text { Latin: } \\
\text { - pagus : territorial } \\
\text { administration } \\
\text { - age : collection }\end{array}$ \\
\hline $\begin{array}{l}\text { Kháng cự } \\
\text { (resilience) }\end{array}$ & $\begin{array}{l}\text { Idea of opposition/resistance } \\
\text { kháng: to resist; to protest } \\
\text { cur : to scold; to oppose; to resist }\end{array}$ & Résilience & $\begin{array}{l}\text { Capacity to adapt and } \\
\text { recover - flexibility }\end{array}$ \\
\hline $\begin{array}{l}\text { Cầu thang } \\
\text { (staircase) }\end{array}$ & $\begin{array}{l}\text { Idea of movement, crossing } \\
\text { cầu: bridge } \\
\text { Thang: ladder, range }\end{array}$ & Escalier & architectural \\
\hline
\end{tabular}

\section{Literature and policy overview}

Community capacity to build within environmental conditions

The capacity of communities to build amid environmental, climatic, and social conditions has been integral to human development, with vernacular architectures or urban typologies interdependently linked to community needs, cultural values and social relationships. Due to their dynamic nature, these local processes are not "anachronistic survivals" of the past but essential considerations for use in sustainable, culturally appropriate architecture [Oliver 2003].

In the VMD, adaptation has always been part of local life, and vernacular processes are still multiform and valuable, providing critical architectural and environmental knowledge [Nguyen Anh Tuan et al. 2011: 2088]. This two-way relationship between people and their living environment is a refreshing approach to dealing with the causes and effects of climate change. Currently drawing mounting attention, community capacity and vernacular processes are increasingly included in emerging theory of climate change and development. For example, porous, sponge cities and naturebased approaches often use vernacular knowledge based on environmental observation and community capacity.

\section{The growing challenge of climate change and its local impacts}

Locally, the most severe impact of climate change is sea-level rise, with nearly $39 \%$ of the VMD estimated to be at risk of flooding from a one-metre sea-level rise (Fig. 3) [MONRE 2016].

Understanding of the growing challenge of climate change and its local impacts is still limited, making it hard to distinguish between effects caused by climate change, anthropic actions, and natural phenomena. Even in the absence of climate pressures, VMD communities have long faced natural disasters [World Bank 2010: 6]. 200 years of anthropic activities have resulted in the survival of only 0.068 million hectares of the delta as primary swamp forest ecosystems [Nguyen Hoang et al. 2016: 2304]. Government policies for resettlement, economic development, agricultural expansion, natural resource exploitation and infrastructure construction have played the most significant role in degrading the delta. 


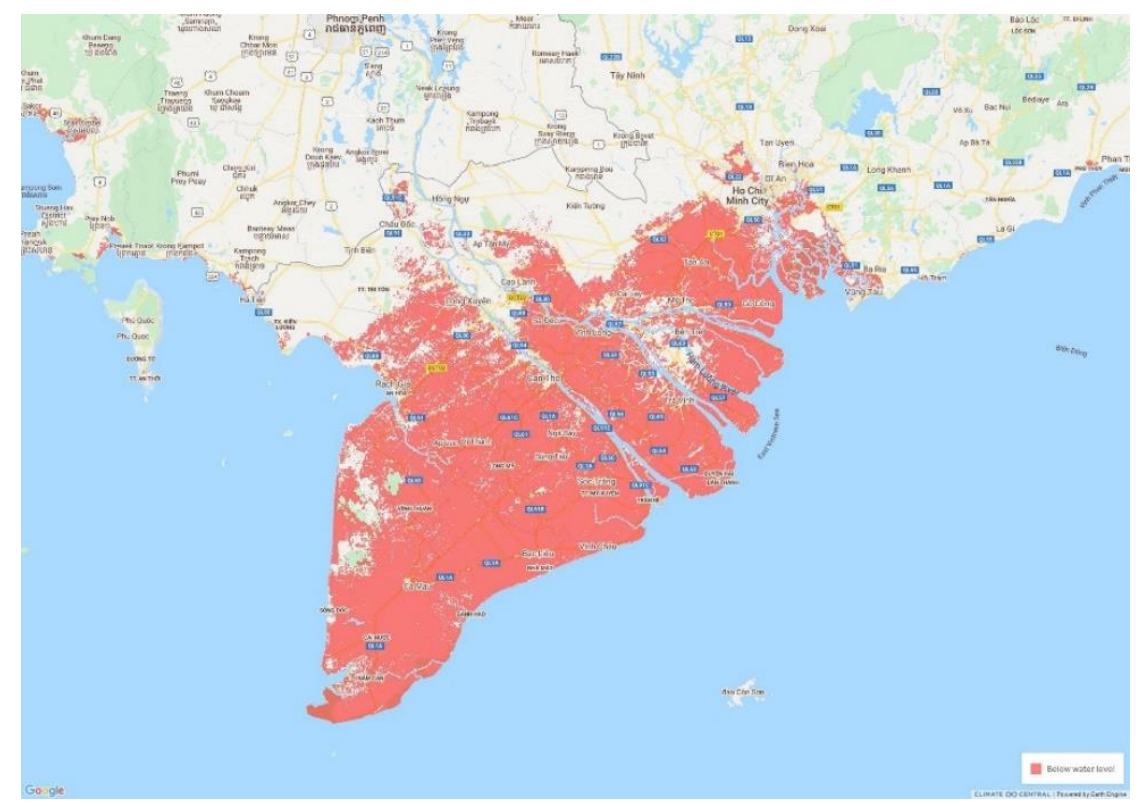

Fig. 3. Sea-level rise impact at the delta scale. The map shows in red areas at risks of water submersion from a one-metre sea-level rise. Source: climatecentral.org

Local authorities still consider climate change through the lens of disaster, producing policy that responds to disaster rather than adapting to climate change. Given that many risks related to climate change are amorphous and draw less attention than disasters, climate change adaptation is given low priority although adaptation requires long-term commitment [Christoplos et al. 2016: 460]. Adaptation has also been used as a political talking point to disempower states of their protection duty in the face of climate change, urging communities to adjust by themselves, forcing adaptation and affecting human rights [Djament-Tran et al. 2011: 22].

\section{Building and housing policies in response to climate change, and their suitability}

Governance at the delta scale is largely fragmented, involving many top-down processes [Smajgl 2018: 6]. Predominantly centralised, this governance reduces the leeway local authorities and residents have to act autonomously and enhance local resilience. Although the Mekong Delta Plan (2013) provides a comprehensive framework with an urban development component, the lack of vertical integration down to the local level affects sectoral action plans [Phan Thi An et al. 2019: 7], consequently reducing the development of effective initiatives. Furthermore, the existing topdown vision does not identify the diversity of contexts, leading to inadequate strategies that are detached from local realities, with little attention paid to social vulnerability or 'soft' adaptation measures [World Bank 2010: 14]. However, the responsibilities of local authorities are expanding following recent measures that decentralise many functions to the district level and that redefine local governance, with the involvement of civil society [Christoplos et al. 2016: 460].

This governance structure directly impacts the suitability of urban and housing policies in response to climate change. Several documents seek to address this issue [Smajgl 2018: 4]. However, economic growth and infrastructure development still dominate the agenda, side-lining building, social and environmental concerns [Fortier 2010]. Recently, international architectural and urban projects have not always been successful in cross-cultural transfer [Vellinga 2005: 5]. For example, VMD resettlement programmes, considered a key strategy for climate change adaptation, have tended to leave shelters little-used or unused, often leading to increased socio-economic vulnerabilities and 
undermining people's ability to adapt [Chun 2015; Miller, Dun 2019: 132]. While this failure is complex, the inability of policymakers and designers to consider holistic cultural needs, expectations, and environmental characteristics is a critical factor.

\section{Findings}

\section{Diversity of options and capacity at local scale}

The first significant finding was the diversity of options, capacity and resources (human and material) mobilised at the local level to accommodate the deltaic system. Chau Doc's urban fringes and riverbanks were striking to observe and demonstrated the wide range of materials and construction techniques used by locals (wood, bamboo, concrete, stone with composite structures: stilts, floating systems, boats becoming houses, vegetal architecture). Focus group discussions revealed that building capacity often reflected the social values of local communities, such as solidarity and mutual assistance. During semi-structured interviews, several households outlined the commitment of family and community structures to building habitats and their ability to design without technical support. This demonstrated persistent local knowledge and agency.

The photographic mapping revealed the creative capacity of communities to live in a changing environment. Buildings were built using low-cost mechanisms to provide climate-friendly settlements, with unique processes such as ventilated floors and adequate spacing between houses to maximise natural cooling, as illustrated below (Fig. 4). Around houses, the photographic mapping also highlighted the use of so-called nature-based solutions. These are now widely recognised internationally as means of developing sustainable systems, based on local ecosystems and the services they provide (for example, bamboo forests for protection from waves, fruit trees to create natural shade and prevent soil erosion).
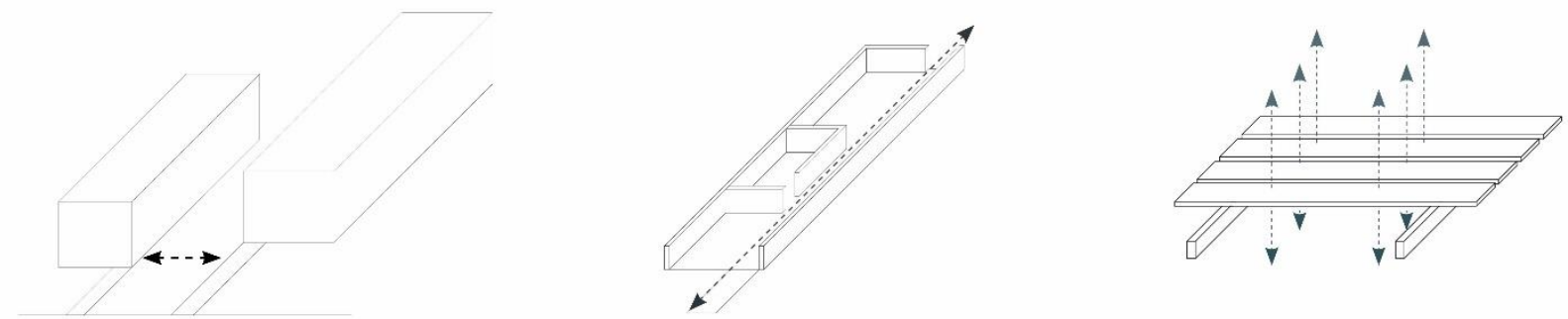

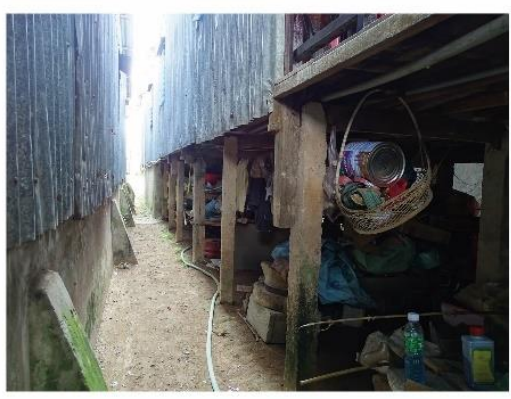

SEMI DETACHED SPACE

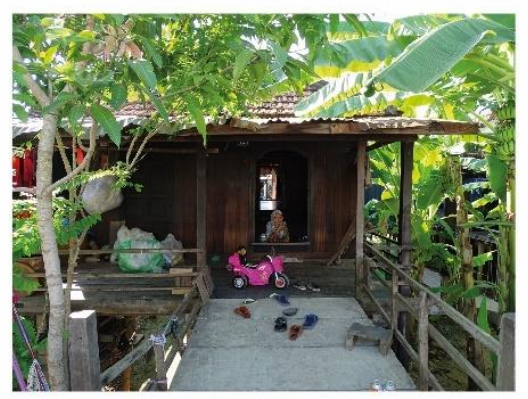

AIR FLOW

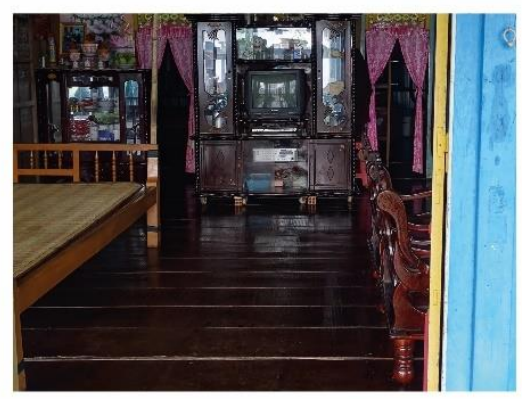

VENTILATED FLOOR

Fig. 4. Examples of building processes used in the VMD. Photos and pictures by the author 
During semi-structured interviews, most interviewees stated that they felt part of a whole system, including their habitat and living environment, and considering the delta an entire territory. As delta areas are interconnected and dependant on physical and geographical plans, this observation was fundamental in revealing the nature of people's 'sense of place', which is reflected in modest and efficient buildings, driven by flexible concepts (stilts, floating surfaces, mobile floors). One respondent indicated that his house was entirely designed to be taken apart and rebuilt elsewhere.

This capacity for adaptation and flexibility was, however, subject to cultural factors. Several migrant communities experiencing high rates of landlessness and dependency on wage labour did not show the same degree of in-situ adaptability, preferring seasonal migration patterns to adapt. Observations in Cham communities have shown their extensive abilities to adapt and live in highly flooded areas, notably due to their marginalisation in at risk areas. Similarly, Khmer groups residing in the delta did not show the same degree of flexibility. Often located in "dry areas", their exposure to climatic hazards was limited, decreasing the necessity for them to develop adaptable housing and reducing their capacity to adapt their buildings.

\section{Degrees of flexibility in housing design}

Interview findings highlighted the lack of urban and architectural regulations, demonstrating the leeway and variability in resultant construction. This vagueness of regulation is considered advantageous to expand local community capacity as people can build as they wish (no respondent reported the obligation to have a "building permit"). For urban fringe houses along canals and rivers, land limits and tenure were challenging to understand, especially among interviewees who had stilt houses. Signposts informing locals of construction limits (for flood risk) appeared along the banks, without being necessarily followed.

Despite presenting opportunities, this lack of guidance and clarity could pose adaptation risks in new urbanised areas if maladaptive approaches are adopted. The use of concrete on entire parcels of land was observed in Can Tho, contributing to soil artificialisation and increasing urban floods risk as illustrated in the following pictures (Fig.5). This example shows the lack of urban regulations to advance water absorption, potentially limiting the adaptive capacity of residents.
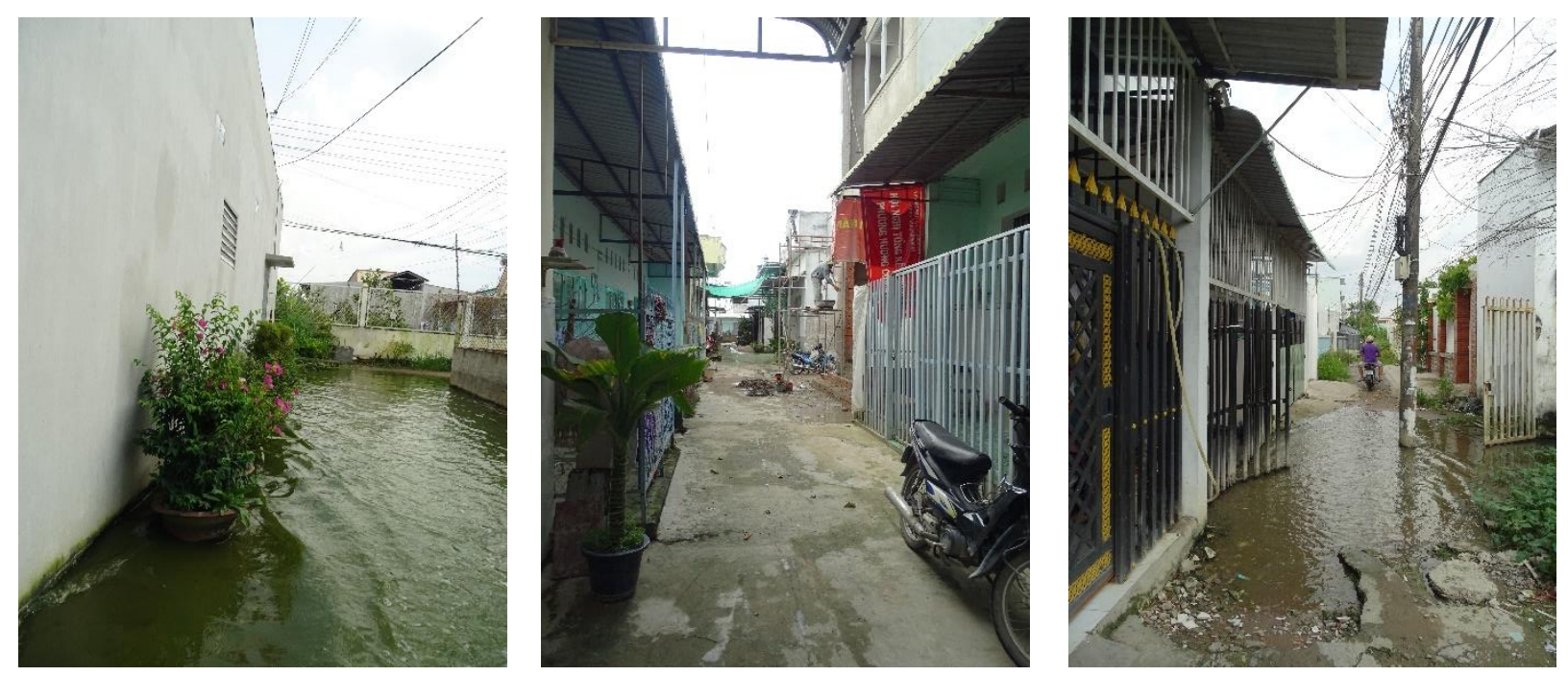

Fig. 5. Newly urbanized areas in Can Tho. Most unused parcels are covered with concrete, and houses have not been elevated. Photos by the author 


\section{Persistent gaps in policymaking}

The above findings identified persistent gaps in policymaking, reducing the architectural and climate resilience of local settlements. As stated in the literature review, a fundamental shift has been made towards developing a more local approach, resulting in a combination of top-down and bottomup strategies at the local scale. However, according to discussions with local authorities and the policy review, current strategies continue to focus on upgrading infrastructure and developing projects designed as one-off adaptation responses along "rigid" lines. In resettlement villages, promoted as an optimum solution, inhabitants reported that many households received low-interest loans to build new homes while some were provided with houses. These were usually unelevated and "rigid", with poor natural ventilation. Most interviewees understood the purpose of the resettlement programme, although many did not consider their previous living areas dangerous. These operations in the observed locations showed that vulnerabilities increased as young residents left for more prominent urban centres, leaving behind children and the elderly with limited access to basic services and economic opportunities. Costs of living also rose due to loan and electricity payments.

Observations showed that land management excludes the most vulnerable making resiliency more difficult. Most respondents in migrant and floating communities near Chau Doc and Long Xuyen urban centres noted difficulties in accessing basic services and land to settle on due to issues obtaining legal documents.

\section{Specific risk perception and misunderstanding of local strategies}

Perception was also a central topic of discussion, including the challenge of perceiving risk and understanding the effects of climate change. Many inhabitants did not see floods as a risk, whereas the current political discourse encourages any activity and projects to protect against them. Another discrepancy was illustrated in group discussions with Can Tho officials, where local authorities could not always differentiate between climate change and anthropic pressures, and little interest was shown in understanding local risk perceptions or community responses. Furthermore, as risk management has always been part of life in the VMD, the over-attribution of climate change as a cause of risks has led to a misunderstanding and misdirection of local communities, who also fail to distinguish between the effects of "normal" phenomena, anthropogenic actions, and climate change.

Language bias was also identified. As shown by the development of the experimental lexicon, several concepts were not always well translated or understood, reinforcing the inadequacy and misunderstanding of climate strategies.

Finally, ongoing social changes have led to a transformative vision of modernity, highly illustrated in new building developments throughout the VMD with the overuse of inappropriate, imported models using western codes and spatial representation. As a result, many vernacular processes have been disregarded, although new models do not facilitate climate change adaptation.

\section{Discussions \\ The potential of local capacity in climate resilience}

Findings showed that local capacity could undoubtedly offer a developmental alternative that is more anchored in local realities than modern developmental approaches. In the VMD, local capacity has demonstrated that environmental knowledge is vital for disaster risk reduction and 
climate change adaptation. By developing flexible in situ architecture and water urbanism with territorial interconnections, communities have developed socially adapted human settlement models that can potentially be reused in adaptation initiatives.

However, several issues challenge such practices. The first limitation is the result of social change linked to the idea of modernity, and access to building resources, in highly anthropized territories dedicated to agriculture. Finding local and sustainable materials is now a crucial issue at the scale of the delta. Besides, urban residents may have more constraints on individual adaptation than rural residents due to land pressures and reduced social capital, curbing opportunities to migrate to "safer areas". Furthermore, newcomers, often migrants from other provinces, have low participation in community activities because many lack legal residence permits which can influence their ability to adapt to their living environment. Although community engagement remains strong throughout the Delta, this growing pattern may limit capacity.

To find the right balance between local knowledge and the desire for modernity, many local architects reuse traditional models by learning from local builders. One of many examples in the VMD can be found in Chau Doc. The housing project of Nishizawa Architects uses codes and materials of local stilt houses (Fig.6). As illustrated below, the architectural form and processes used, especially for ventilation and cooling, are characteristic of local housing and enhance the building's comfort while having a modern appearance.
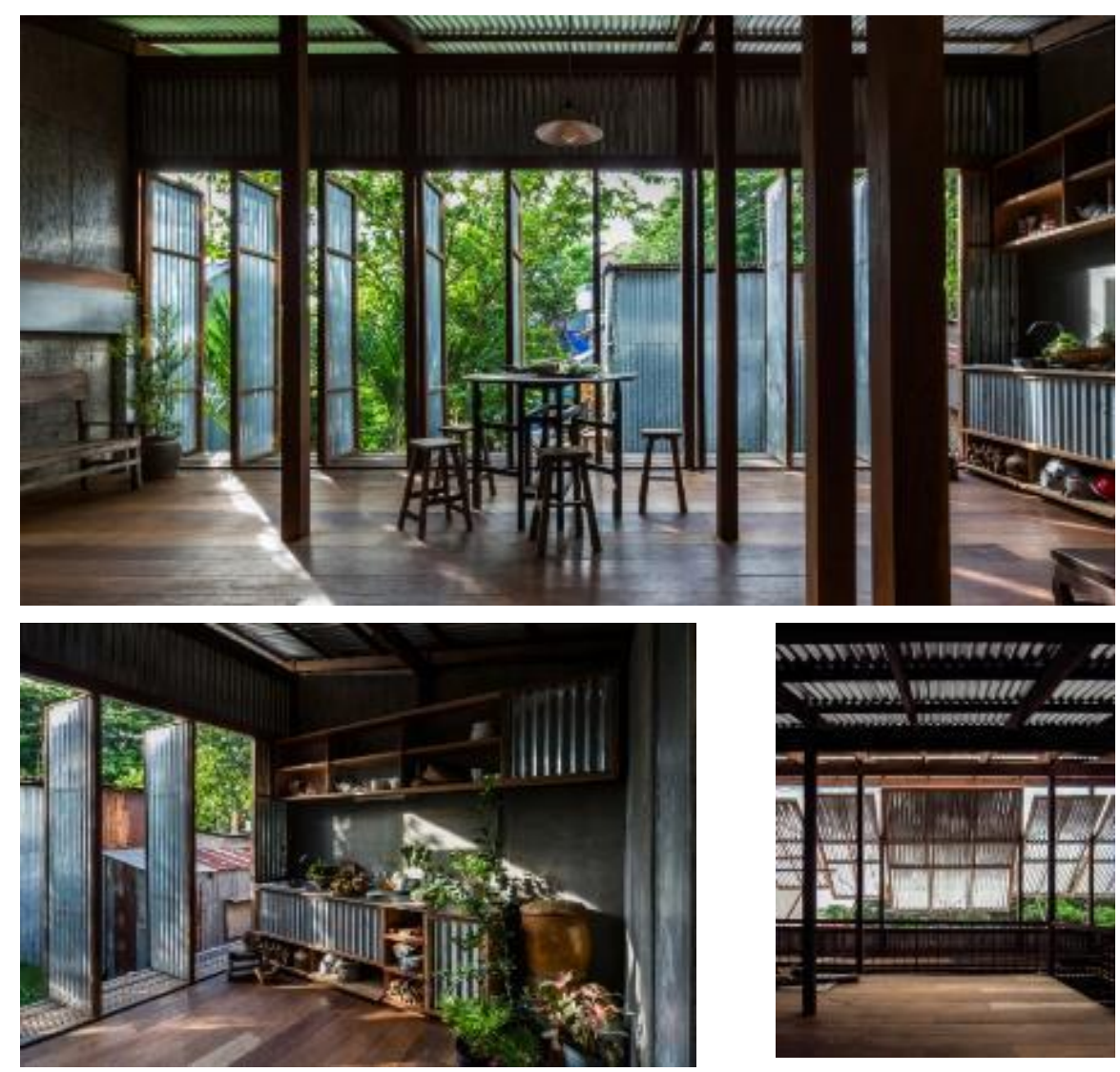

Fig. 6. Architectural details of the "revisited" stilt house of Nishizawa in Chau Doc. The house looks like all the others (size, shape, materials) from the street while being environmentally friendly and adapted to modern life. Resource: https://www.nishizawaarchitects.com 
Finally, new concepts based on local capacity and vernacular housing are increasingly emerging in delta settlements. The concept of porous cities or nature-based solutions often refers to vernacular ecological knowledge, which is based on observations of the environment and community capacity and can strengthen the human-environment relationship.

\section{The challenge of integrating local knowledge and community capacity into policy}

Integrating local capacity and knowledge into policy is a critical challenge for the selected area. This is especially the case, as top-down governance and sectoral fragmentation result in slow policymaking and because there is no comprehensive set of guidelines for sustainability in Vietnam, due to the diversity of contexts [Nguyen Hong Trang et al. 2017: 8]. As many Vietnamese regions are likely to experience unique climate impacts, a single national adaptation policy will not advance resilience. This highlights the need for autonomous initiatives, community and individual actions, and gender and ethnic sensitivity.

As explained above, the poor distinction between the effects of climate change and other influences contributes to a weak understanding of climate change impacts. For example, some of the urban strategies reviewed did not identify land subsidence (due to decades of water pumping) as an anthropogenic influence. Climate change is also used as a scapegoat for environmental mismanagement, posing direct threats to the full and effective enjoyment of many human rights. The climate crisis considerably impacts human settlements and cities, consequently calling for coherence between climate and housing policies in order to guarantee the right to housing. However, given the uncertainty and invisibility of ongoing changes, climate resilience is often negotiated and not prioritised. In the VMD, resettlement has become a preferred tool with adverse effects on local capacity.

\section{Perception barriers}

Findings highlighted several barriers to community capacity due to risk perception and language bias. While risks have always been part of life in the VMD, the ubiquity of climate change in the media and local discourse has led to misunderstandings within local communities. Semistructured interviews illustrated several issues in concept translation, influencing strategies at all scales. When translating global concepts into Vietnamese, semantic nuances can be lost, as was the case with "resilience". Recognised as the "capacity of social, economic and environmental systems to cope with a hazardous event", resilience is often translated as "kháng cự" in Vietnamese, conveying the idea of resistance and rigidity. Failing to consider semantic elements in communicating sustainability concepts can hinder effective discussion among local and international actors.

Moreover, local perceptions and capacities are highly influenced by a specific idea of modernity resulting in the adoption of unsuitable models, often imported and climatically inappropriate. This is particularly the case in VMD settlements and significantly impacts the construction market and living environments. The construction of "rigid houses" with non-flexible structures is now a common practice. Some interviewees in Long Xuyen explained that "fencing, a concrete house, air conditioning and tiled floor were important as it looks nicer when we invite guests at home". However, the mass use of materials such as concrete and the development of imported models directly affects mobility, lifestyles, and the definition of private and public space. Abrupt changes in building practices can lead to abrupt social changes, local knowledge loss, and increased inequality. 


\section{Conclusion}

This paper identified the building processes of communities in the VMD and their drivers in selected delta settlements to reflect on their potential use in response to climate change.

The research investigated local capacity and their socio-technical dynamics, limits and the reasons for their limited integration into local strategies. While loose housing policy has allowed for a diversity of approaches, findings also showed persistent gaps in policymaking and specific risk perceptions also adversely influenced the implementation of local strategies. The discussion highlighted the potential of local capacity in climate resilience. It also demonstrated the challenge of integrating local knowledge into policy, and the barriers of perception affecting how communities build settlements in the VMD. The paper concludes by emphasising the need to advance alternative housing and urban adaptation mechanisms considering local knowledge and advocating for the urgent need to develop more localised, integrative and multisector policies to better build south Vietnamese settlements.

\section{References}

Biggs D. (2011). Fixing the Delta: History and the Politics of Hydraulic Infrastructure Development and Conservation in the Mekong Delta, in: Environmental Change and Agricultural Sustainability in the Mekong Delta. New York: Springer, 35-44.

Biggs D., Miller F., Hoanh C.T. et al. (2009). The Delta Machine: Water Management in the Vietnamese Mekong Delta in Historical and Contemporary Perspectives, in: Contested Waterscapes in the Mekong Region: Hydropower, Livelihoods and Governance. London: Earthscan, 203-225.

Christoplos I., Le Duc Ngoan, Le Thi Hoa Sen et al. (2016). The Evolving Local Social Contract for Managing Climate and Disaster Risk in Vietnam. Disasters, 41.

Chun J.M. (2015). Planned Relocations in the Mekong Delta: A Successful Model for Climate Change Adaptation, a Cautionary Tale, or Both? Brookings LSE project on internal displacement. Washington, DC: Brookings Institution.

Djament-Tran G., Le Blanc A., Lhomme S. et al. (2011). Ce que la résilience n'est pas, ce qu'on veut lui faire dire [What Resilience Is Not, What We Want It to Say]. hal-00679293

Fortier F. (2010). Taking a Climate Chance: A Procedural Critique of Vietnam's Climate Change Strategy. Asia Pacific Viewpoint, 51: 229-247.

Garschagen M. ed. (2010). Urban Upgrading and Resettlement of Slum dwellers in the Mekong Delta: Long-Term Sustainability or Vulnerability Pitfall? Hanoi.

Miller F. (2007). Seeing 'Water Blindness': Water Control in Agricultural Intensification and Environmental Change in the Mekong Delta, in: Environment, Development and Change in Rural AsiaPacific: Between Local and Global. London: Routledge, 186-207.

Miller F., Dun O. (2019). Resettlement and the Environment in Vietnam: Implications for Climate Change Adaptation Planning. Asia Pacific Viewpoint.

Ministry of Natural Resources and Environment (MONRE) (2016). Climate Change and Sea Level Rise Scenarios for Viet Nam. Hanoi: MONRE.

Nguyen Anh Tuan, Tran Quoc Bao, Tran Duc Quang et al. (2011). An Investigation on Climate Responsive Design Strategies of Vernacular Housing in Vietnam. Building and Environment, 46, (10: 20882106.

Nguyen Hoang, Dargusch P., Moss P. (2016). A Review of the Drivers of 200 Years of Wetland Degradation in the Mekong Delta of Vietnam. Reg Environ Change, 16: 2303-2315.

Nguyen Hong Trang, Skitmore M., Gray M. et al. (2017). Will Green Building Development Take Off? An Exploratory Study of Barriers to Green Building in Vietnam. Resources, Conservation and Recycling, 127: 8-20. 
Oliver P. (2003). Dwellings: The Vernacular House Worldwide. London: Phaidon.

Phan Thi An, Tran Trong Hanh (2019). Ecolo-Urbanistic Conditions of Territorial Zoning of the Settlement System in the Mekong Delta, Vietnam. E3S Web of Conferences.

Smajgl A. (2018). Climate Change Adaptation Planning in Vietnam's Mekong Delta. Case Study. Washington, DC: Long Term Strategies Project.

Tran Thong Anh. (2019). Land Use Change Driven Out-Migration: Evidence from Three Flood-Prone Communities in the Vietnamese Mekong Delta. Land Use Policy, 88.

Tran Thong Anh (2020). From Free to Forced Adaptation: A Political Ecology of the 'State-SocietyFLood' NExus in the Vietnamese Mekong Delta. Asia Pacific Viewpoint, 61.

Vellinga M. (2005). Anthropology and the Challenges of Sustainable Architecture. Anthropology Today, 21, 3 June.

World Bank (2010). The Social Dimensions of Adaptation to Climate Change in Vietnam. Washington DC: The World Bank.

\section{Author:}

Marion Reinosa, PhD Candidate in Architecture, Research Laboratory in Architecture, Architecture School of Toulouse. Email: marion.reinosa@ toulouse.archi.fr

Article history:

Received: 6 September 2021

Received in revised form: 19 October 2021

Accepted: 12 December 2021 